\title{
A stakeholder perspective on Process Improvement Behaviours: Delivering the Triple Bottom Line in SMEs
}

Dr Rupert L. Matthews

Nottingham Trent University

Rupert.matthews@ntu.ac.uk

Dr Ying Kei Tse

The University of York

Mike.tse@york.ac.uk

Matthew O'Meara Wallis

Nottingham Trent University

Matthew-omeara.wallis@nut.ac.yk

Dr Peter E Marzec

Nottingham Trent University

Pete.marzec@elmprofessional.com 
Abstract:

The primary focus of operations management is to add value through operational processes. Considerable attention has been given to using process improvement (PI) techniques to reduce costs and time, in order to develop a competitive advantage for the wider organisation. However, this narrow definition of value at times overlooks the Triple Bottom Line (TBL) which can result in a number of unintended consequences, specifically issues related to environmental and social measures of performance. To address this, a stakeholder theory lens will be used to analyze PI activities within the context of small and medium sized enterprises (SMEs). The TBL will be used to complement the stakeholder perspective, to interpret the benefits that are realised from PI activities. This paper highlights both the direct benefits from PI as well as more indirect benefits realised by involving a selection of salient stakeholders in PI. It will show how a developed view of PI can provide an important mechanism for delivering improvements to a firm's TBL. The work concludes by highlighting the contributions made to both PI practice and stakeholder theory, while acknowledging the need for more research on PI, both from a stakeholder perspective, and how it impacts a firm's TBL.

Keywords: Process improvement, Small and Medium-Sized Enterprises, Stakeholder Theory, Triple Bottom Line 


\section{Introduction}

Process improvement (PI) represents a central topic of operations management; it allows firms to adapt to account for feedback from customers, as well as realise benefits from identified opportunities. PI has been identified as a key practice for identifying and removing waste from operational processes and improving the consistency of operational processes (Powell 1995). Operational improvement frameworks that remove and reduce waste of operational systems have also been considered to contribute positively to the environment by reducing resource usage (Dües et al. 2013). However, popularized case studies and research into operational improvement techniques illustrate that the implementation of improvement techniques do not consistently contribute to improved firm performance across a range of measures (Powell 1995, Tyler and Wilkinson 2007). To ensure appropriate focus was given to the aims of improvement activities, some improvement frameworks emphasize linking operational improvements to organisational strategy and the economic bottom line (Schroeder et al. 2008). Unfortunately, this focused attention on cost savings can overlook other critical measures of performance as well as key stakeholders that both contribute to, and realise benefits from, organisational activities (McAdam and Lafferty 2004, Chakravorty 2009). As a result, without giving attention to more inclusive measures of performance that account for the triple bottom line (TBL), operational improvement techniques have not been able to address problems associated with realizing and sustaining benefits from operational improvement activities.

The myopic focus on improving process consistency can reduce the extent to which firms are able to adapt to account for external requirements (Benner and Tushman 2002). By pursuing incremental forms of improvement, that look for short-term gains, firms may tend to forfeit longterm operational, social and environment measures of performance. Research illustrates how corporate waste reduction activities can cause severe organisational issues, such as subversive behavior of operational staff (Tyler and Wilkinson 2007). These findings are consistent with stakeholder theory that suggests that firms engaging in effective stakeholder management will, in the long run, outperform firms that do not (Freeman 1984, Donaldson and Preston 1995). One of the most popular approaches to developing organisations in a sustainable manner, derived from a stakeholder perspective, is the TBL (Norman and MacDonald 2004, Elkington 1999). Whilst the bottom line is necessarily economic, TBL enwraps two additional dimensions of environment and society to the economic (Ten Bos and Bevan 2011) leading to considerable popularity with practicing managers. The over focus of PI on the improvement of operational efficiency results in other stakeholders being largely ignored. Developing processes that accommodate more salient stakeholders is more ethical. Furthermore, it enables the identification of additional and even crucial PI opportunities, which can positively impact economic, as well as influence social and environmental performance (TBL). In the current market environment, there is a requirement for firms to operate in a sustainable manner, showing greater consideration of salient stakeholders and delivering on the TBL (Dües et al. 2013, Kannan 2017). Reflecting this, Hollos 
et al. (2012) illustrated how involvements with suppliers could make a significant contribution to a firm's economic and environmental performance.

To address this gap within existing PI literature, this paper will demonstrate that taking a stakeholder perspective, as defined by Freeman (1984, Freeman et al. 2010) and Donaldson and Preston (1995), will support the development of understanding of PI activities within Small and Medium sized Enterprises (SMEs). Within this analysis, specific attention will not only be given to considering the involvement of various stakeholders, but PI outputs that relate to TBL measures of performance (Elkington 1999). SMEs are considered a particularly relevant context in which to explore stakeholder's role in PI, due to the accepted attention of such firms on revenue generating processes (Hudson et al. 2001), so potentially being more likely to overlook the needs of other stakeholders. Understanding the contribution and benefits realised from PI by a variety of stakeholders in SMEs will illustrate PI's potential contributions within other contexts that require greater awareness of multiple organisational stakeholders. The work will also explore the relevance of this influential theoretical concept to the context of PI, in order to determine how stakeholder theory insights and attention on the TBL can increase success in SMEs and PI more generally (e.g. Shamsuzzoha et al. 2016). The research will contribute evidence to answering the following research question:-

RQ: How does stakeholder theory contribute to delivering the Triple Bottom Line through Process Improvement in SMEs?

The following section reviews literature on PI to explore how the work relates to concepts of stakeholders and the TBL, before exploring how the work on PI explicitly draws from the concept of stakeholders including the presentation of stakeholder theory as the lens through which the research will be conducted.

This section is followed by a brief outline of methods employed in the research, which precedes presentation of empirical findings. The paper concludes by discussing the relevance of the findings to both PI practice, stakeholder theory and the TBL. This is followed by the presentation of a conceptual model of the contribution of various stakeholders to PI within SMEs that categorize outputs in relation to the TBL, before proposing avenues for further research.

\section{The Role of Stakeholder Theory and the TBL within PI}

The following literature review explores how research focused upon PI draws upon stakeholder theory and the TBL. This work will be compared with literature that presents stakeholder theory and the TBL, to discuss the relevance of these concepts for SMEs. To account for the changing operating environment, it is necessary for firms to continually and deliberately adapt operational processes. This enables them to change products to account for new market conditions, changing 
customer requirements and competitor behaviours. Consequently, within modern business, effective PI, that accounts for the needs of salient stakeholders, is central to operations management (Anand, Ward, and Tatikonda 2010). This perspective is rather broader than established definitions of PI, focusing on PI as primarily a "means of improvement" or "an outcome" related to reductions in waste, cost or cycle time (Barnett 2007, Matthews and Marzec 2017). Much less attention has been given to how a variety of parties contribute to PI activities, why they contribute, and the benefits that realised from involvement.

Quality management practices provides a framework that enables firms to effectively pursue PI. However, firms who have performed quality management practices well and have won quality awards do not necessarily experience the associated improvements in firm performance (Powell 1995). Firms implementing improvement initiatives may focus upon the improvement of operational processes, but overlook the requirements of relevant stakeholders. This has been found to lead to reductions in innovative performance (Benner and Tushman 2002) and resistance from operational staff (Tyler and Wilkinson 2007). This insight begins to identify some problems associated with PI where there may be a tendency to focus on particular stakeholders (upper management), while overlooking others (customers and employees). To address such issues, Elkington (1999) proposed the TBL of corporate performance, that highlights the need to allocate resources and measure the contribution to multiple stakeholders.

To explore the relevance of these observations and the relationship between Total Quality Management (TQM) and performance, Powell (1995) and later Samson and Terziovski (1999), tested the strength of connections between specific quality management practices and firm performance. The surveys were based upon assessment frameworks, such as the Malcolm Baldrige National Quality Award (MBNQA) to determine what quality management practices consisted of and their relationships with organizational outcomes. Both Powell (1995) and Samson and Terziovski (1999) found that the aspects of TQM that engaged with internal stakeholders (leadership, people management and customer focus) were significantly related to performance. This work focused upon the direct relationships between quality management practices and performance, meaning attention was not given to how practices that involved salient external stakeholders contributed to PI and whether this affected PI's relationship with performance. Nonetheless, both works highlighted that working with key stakeholders, such as suppliers and customers, positively impacted firm performance. Interestingly, within Samson and Terziovski (1999), strategic planning made reference to more general stakeholders, and Powell (1995) stating "TQM requires a complete restructuring of social relationships both within the firm, and among the firm and its stakeholders" (p.27). Such findings and insight were later substantiated empirically by Kaynak (2003), that demonstrated strong contributions of customers, employees and suppliers to data and process management activities (PI). However, the work left opportunities to explore the role of stakeholder within PI that have recently been highlights by Aquilani et al. (2017), but also the need to develop understanding of the potential contribution of stakeholder theory within 
this context. This antecedent literature provides a strong rationale for the exploration of benefits stakeholder theory may provide PI, and vice-versa.

Formal organizational systems and structures are a key part of quality management practices. The structure of these practices help integrate the requirement to involve, engage and develop operational staff, which is formalized within organizational policies and procedures (Schroeder et al. 2008). Within Six Sigma, the structured PI process stipulates involvement of senior management, customers, suppliers and process owners (De Mast and Lokkerbol 2012). Notwithstanding such greater attention on organizational stakeholders, more critical investigations of Six Sigma highlight difficulties that can occur when balancing the achievement of bottom line savings with the needs of other stakeholders (McAdam and Lafferty 2004). Chakravorty (2009) also illustrated how Six Sigma initiatives can fail if they do not provide economic benefits to key stakeholders, that can reduce the credibility of PI activities. Similarly, unless firms are able to demonstrate outcomes of corporate social responsibility initiatives, the initiatives may lose creditability with important stakeholders (Moratis 2017).

This short overview of PI begins to present how PI activities need to be more than tightly defined tools and techniques, focused wholly on the delivery of cost savings. Instead it suggests that PI needs to be defined as a complex process that requires involvement of a range of stakeholders and contribution of a variety of benefits, which in turn may contribute to improved firm performance. Due to the involvement of a variety of parties, PI can be developed from more than simply a means of improving narrowly defined process attributes, highlighting the importance of PI to contribute to the TBL. By requiring the involvement of management, engagement of employees and contributions from suppliers and customers to activities, there are greater opportunities to realise improvements, allowing the nature of PI to be broadened considerably. The next section introduces stakeholder theory as a means of structuring and interpreting PI practices.

\subsection{Stakeholder theory and the Triple Bottom Line}

While an ever present part of business, a stakeholder perspective was formalized by Freeman (1984), suggesting the complexity of the (then) modern environment required greater awareness of external parties than the "production model" of the firm, that only considered process inputs and outputs. Stakeholder theory states that firms should not only make decisions based on shareholder wealth maximization, for them to ensure both short and long term firm health. Stakeholder theory states there are a range of stakeholders that need to be considered, which both influence and are influenced by business decisions, not simply those who depend on the business for their survival (suppliers, employees and customers). Stakeholder theory suggests that firms effectively engaged in stakeholder management give all parties effecting and being affected by their actions consideration for their own sake and act accordingly. 
In developing this perspective, Donaldson and Preston (1995) stated that firms which engaged in effective stakeholder management would perform better than those that did not. As a result, the short-term requirements of profit were satisfied, but not at the expense of worker remunerations, environmental damage, the needs of the customers or non-government organisations, thus promoting sustainability of the business and its ecosystem (Hasnas 2013). Elkington (1999) further refined aspects of the stakeholder perspective, by suggesting that organizational performance should be defined in terms of social and environmental, as well as economic (i.e. the TBL). These framework ensures stakeholder consideration through measuring organsiational outputs, illustrating the strong links between the two concepts. However, while the TBL has been widely adopted by corporations, Norman and Macdonald (2004) state the need to integrate such reporting methods with the aims of the business and salient stakeholders to ensure they deliver the aims of sustainability initiatives. Unfortunately, while the relationship between stakeholder involvement and firm performance have now long been established (Freeman 1984), the theoretic justification and practical underpinnings for this relationship are not wholly warranted.

Despeisse et al. (2012, p.361) suggest that while organizations present significant improvements across a range of environmental performance metrics, little information is provided on the mechanisms through which they are achieved. To provide justification for the relationship, Barnett (2007) drew from complementary theoretical perspectives, suggesting that more effective stakeholder engagement could reduce transaction costs by increasing trust, but also help create a competitive advantage by learning from external parties. Rather than focusing on the reduction of variation or removal of waste from internal processes, broader definitions of PI are necessary to capture both the tangible and intangible outputs that contribute to firm performance. This view was put into the context of operations by Dües et al. (2013), who considered the need to define improvements in terms of the TBL to ensure operations improvement frameworks delivered more than simply cost reductions through the removal of waste.

Interestingly, in exploring the link between corporate social responsibility and firm performance, Barnett (2007) made direct reference to the concept of PI. However, PI was tightly defined in terms of efficiency improvement and waste reduction. As a result, it was considered to have a limited relationship with both stakeholder relations and social welfare, key elements of the TBL. Barnett's (2007) view of PI is thus similar to that used in operations management, with the current research aiming to expand the definition of PI to include a greater range of stakeholders and give greater emphasis to the delivery of social and environmental benefits. With a broader definition of PI, the current work thus has potential to increase the relevance of the practice of PI to explore practices related to delivering improvements to the TBL.

\subsection{Process Improvement, Stakeholders and the TBL in SMEs}

Limited research has then been done on PI within the context of SMEs (Matthews et al. 2017). Hudson et al. (2001) outlines how processes of financial measurement had been well developed 
within SMEs, due to the requirements of external stakeholders. However, they state SMEs give less attention to operational and very limited attention to social or environmental measures of performance, thus overlooking the TBL. While focusing on the improvement of cost based measures of performance, Kumar et al. (2006) stated this was due to the need for SMEs to focus on achieving a quick return of investment, giving less attention to strategic forms of improvement. Panwar et al. (2016) and Moratis (2017) stated that SMEs tended to have less pressure to present social measures of performance, due to those external stakeholders with interest in social measures of performance (e.g. NGOs) paying less attention to SMEs. However, showing similarity with Barnett (2007), Panwar et al. (2016) stated that SMEs who engaged with a variety of external stakeholders were better able to differentiate themselves from competitors. Due to this reduced expectation to deliver TBL improvements and the need to focus on direct revenue generation, SMEs provide an interesting context in which to investigate the delivery of TBL improvements as well as stakeholder theory. By understanding the role, contribution and benefits realised by a variety of stakeholders in a context that does not need to give attention to these forms of improvement, insight can be developed to understand the role of PI in delivering improvements in more complex organizational settings.

Addressing the research question fills gaps within existing literature, by attempting to extend the use of organisational theories within operations management. Walker et al. (2015) highlighted the potential to draw from theories that consider how external pressures affect changes to internal processes. A stakeholder theory perspective can help to address issues with organisations implementing PI, preventing them from overlooking the requirements of the external environment. Reflecting on work focusing on operational improvement in particularly complex operational environments, there is a risk that overlooking external stakeholders can result in organizations that are "internally efficient, but externally ineffective" (Osborne et al. 2015, p.424). This will be addressed by exploring PI practices within SMEs, employing a stakeholder theory and TBL lens to interpret how stakeholder contribute to and benefit from the PI process, in terms of economic, environmental and social performance. The next section reports on the research methodology used to explore PI within SMEs, before the subsequent section discusses PI activities in terms of the involvement of various organizational stakeholders and the benefits they realised from involvement.

\section{Research Approach}

The approach taken to the research was an exploratory, theory development case study approach (Voss et al. 2002, Yin 2009, Childe 2011), focusing on developing PI theory, informed by stakeholder theory and the TBL. Six SMEs were identified and selected within the British Midlands, from a business-to-business database, which was considered a suitable sample for developing existing theory (Eisenhardt 1989). Firms were selected not only due to their size and location, but also due to their involvement in some manufacturing and possession of an ISO9001 accredited quality management systems. This selection criteria supported exploratory research with firms that were geographically close (Stuart et al. 2002), had tangible products and processes to discuss within interviews, supported by audited operational procedures to facilitate 
comparison between firms (Benner and Veloso 2008). Out of the companies involved in the research, only one was also accredited for the environmental standard, ISO14000 (see table 1), which was a result of the environmental performance of their construction projects being a requirement of their customers.

Drawing from an interpretivist perspective (Radnor 2001), discussions on PI were initiated by asking questions about how operational problems were solved, emphasizing how the perceptions of those involved in the process determined how PI was defined (Noke and Hughes 2010). Due to the quality management system in place, changes to operational processes needed to be made to operational procedures to evidence changes, to maintain conformance and attempt to prevent problems recurring. To achieve this, it was necessary for those salient internal and external stakeholders to be informed of changes to enact and communicate actions to affected parties. PI was also discussed in terms of more proactive changes to processes and products, that resulted in the reduction of product cycle times, reductions in material waste or improvement to process consistency, all consistent with established definitions of PI (Matthews and Marzec 2017). Table 1 provides a summary of the case database and the interviews conducted with the 6 case companies. The majority of interviews were conducted over a period of 7 months with 4 follow up interviews conducted with BC, IJ1, IJ2 and EM1 one year after the first interview to gain feedback and confirmation of initial research findings from the project.

** insert Table 1 about here**

While the analysis provided insight to practice in terms of structuring what constitutes PI, this was viewed as in initial stage, supporting the description of practice (Handfield and Melnyk 1998). To extend the insight, it was necessary to carry out finer grained analysis, allowing the development of new perspectives on PI in SMEs, which was done through the use of a further, theoretical analytical lens (Amundson 1998). The stakeholder perspective on PI both allowed for the process-based nature of operations management (Amundson 1998, Boer et al. 2015), but also the need to relate internal improvement activities to the wider horizon of those salient stakeholders affected (Walker et al. 2015).

Through initial analysis of PI, within case analysis provided the basis for firm specific case studies. This gave an overview and structure of PI activities within each firm and the benefits that were realised. Within the secondary analysis, the role of various parties emerged, in terms of their role and contribution to PI, whether in terms of internal stakeholders (management or staff), direct external stakeholders (suppliers or customers) or indirect external stakeholders (consultants or community stakeholders). While this was an observation within initial analysis, the data on PI was re-analyzed from a formal stakeholder theory perspective (Freeman 1984, Donaldson and Preston 1995) in order to build understanding of the role of a range of stakeholders to PI and process outcomes. In comparison to the PI findings, rather than only considering the benefits realised by the focal firm, contributions and benefits were deliberately 
considered for each stakeholder. This process was further enhanced by interpreting outcomes from a TBL perspective (Elkington 1999), which supported the categorization of the different forms of benefits that were realised by the various stakeholders. Viewing PI as both the activities that result in change, and benefits realised from those changes is consistent with stakeholder theory's position that promotes the "achievement of various corporate performance goals" (Donaldson and Preston 1995, p.67).

By not taking stakeholder theory as the primary analytical framework, stakeholder theory did not explicitly inform the data collection process. This research approach ensured interviewees were not guided or directed towards discussions about particular stakeholders, instead the role of stakeholders could be drawn from discussions about practice (Radnor 2001). Drawing on Panwar et al. (2016) and reflecting the size of the firms involved in the research, SMEs are less likely to be of interest to stakeholders such as civil society organisations or pressure groups compared to large firms. Combined with SME's focus on the financial measurement of revenue generating processes (Hudson et al. 2001), the majority of stakeholder attention was on those stakeholders who were directly involved in and affected by PI. Rather than a full stakeholder perspective, this is more in line with Freeman's $(1984$, p.6) managerial view, that accounts for those most salient stakeholders who are the employees, customers, suppliers and owners. This perspective on PI does however provide useful insight to the practices and parties involved in PI within SMEs, consistent with the exploratory nature of the study.

The following section provides an overview of the different stakeholders involved in PI and their role within the 6 case companies. Attempting to build upon stakeholder theory, attention was not only given to the direct relationship between the stakeholders and PI activities, but also the relationships between identified stakeholders, with the associated impact of this on PI activities. Rather than attempting to present within case analysis, for brevity, the discussions will focus on the contribution of stakeholders to PI across the case companies.

\section{Case Evidence}

Across the case companies, the involvement of stakeholders in PI activities was varied, from transactional involvement with materials suppliers (IJ1 and SI2) to close involvement with customers (BC, IJ2 and EM1). Taking primarily a managerial view of stakeholders in the context of PI, the following sections identify and discuss the roles of various stakeholders within the case companies. These are presented as internal and external (direct and indirect) stakeholder, with the relationships between the internal and external groups emphasized within discussions and presented within a conceptual model (Figure 1).

\subsection{Internal Stakeholders}


Internally, management played a critical role in providing the necessary organisational infrastructure to systematically make PI. Management also played an important role in creating the necessary social environment within the organisation where PI was viewed by operational staff as an important activity and one that attention should be directed towards. Due to operational staff playing a critical role within the production/delivery process, engaging with this stakeholder was necessary to ensure they adhered to the quality management system. This promoted consistency of outputs and enabled deliberate changes to be made to processes. Without such attention, EM2 and IJ1 provided examples of operators rejecting changes to procedures, even when they were required to resolve operational issues, customer requests or reduce process waste. In EM1, BC and IJ2, direct support from management and engagement of operational staff in improvement activities was described as creating a more receptive work force, willing to change practice as well as contribute ideas to the improvement of operational processes.

To augment management resources directed towards improvement, and extend the resources of operational staff, some firms had dedicated improvement staff, tasked with making improvements to processes, products and implementing new systems (BC, EM1, IJ1 and SI). Rather than focusing only on resolving production issues, these members of staff also worked on redesigning products to make them easier to manufacture or reduce their cost. Interestingly, within each firm, it was not necessarily the presence of the improvement personnel, but how the improvement personnel engaged with operational staff that appeared to determine whether improvements were made to operational processes. Within IJ1 in particular, operational staff resisted changes in practice, meaning improvements that were made by dedicated personnel were rejected. This situation emphasized the need for management to support, justify and potentially mandate improvement, by translating the needs of external stakeholders into motivators relevant to operational staff. In each case, management, operational staff and dedicated improvement personnel benefited socially from involvement with PI, through personal achievement of solving problems while also extending and applying their own process knowledge. In certain cases, improvements resulted in economic benefits that enabled increases in pay (IJ2), in others, reductions in process waste and energy consumption provided environmental benefits (BC, EM1 \& EM2).

\subsection{External Stakeholders (direct and indirect)}

Building upon the support management gave internal stakeholders, management also represented a key factor in terms of bringing external stakeholders into the PI process. Managers determined the type of work the firm carried out, which in turn determined the level of involvement with customers during the introduction/delivery of new work. Through close involvement with customers, personnel in BC, IJ2 and EM1 were able to identify PI opportunities while discussing product designs. The close involvement also ensured any changes that were made to product designs or processes did not adversely affect customers, facilitating a variety of TBL benefits 
from PI. While involvement with customers enabled PI within some firms, based on the types of new business introduced, some companies had fewer opportunities to make improvements. For example, certain firms were unable to make changes to the product or process without gaining extensive approval from their customers, with tooling and material supplier choices being set by customers (IJ1). Alternatively, customers tightly defined the design of a solution and choose suppliers based on their ability to deliver that solution at an appropriate cost and to a defined timescale (SI). Both situations meant that without extensive design revisions and approvals, some firms had very limited opportunities to make changes or improvements to product and process designs. Compared to involvement with customers contributing to PI activities, this insight highlights how the type of customers selected by management has a dramatic impact on customers' contribution to PI activities and opportunities for operational staff to contribute to PI.

Due to the size of SMEs, suppliers who contributed directly to the production process played a critical role in allowing the SMEs to focus on core activities. These took three main forms; (i) Involvement with materials suppliers allowed the direct reduction of costs by purchasing from lower cost suppliers or more effective purchasing practices to reduce costs with existing suppliers (e.g. bulk buying) (BC, EM1, and IJ2). (ii) Support from productive service suppliers, who were employed to increase the scale of resources by acquiring additional, similar resources to deliver large orders by outsourcing production (BC and EM1). This allowed EM1 to make use of opportunities that arose, even when there were insufficient internal resources to be able to deliver orders within the agreed timeframe. (iii) Involvement with equipment suppliers provided both the direct contribution of increasing machine capabilities (updated machinery) and the training supplied to operational staff to operate the new machinery. The combination of these final two forms of support from equipment suppliers provided the human capital necessary for revising, refining and improving existing manufacturing techniques to reflect the capabilities of newly acquired equipment and realise benefits through PI.

In each of the three forms of supplier involvement, the suppliers themselves also benefited from involvement with the case companies. In addition to the direct benefits of the value of the business associated with involvement, they were able to accumulate knowledge about their customer's operation and the end customer's requirements. This learning process allowed suppliers to learn what additional support they may be able to provide their customer, enabling suppliers to involve themselves and contribute to further improvements. BC referred to attending trade shows to identify new, green technologies that by working with suppliers could be integrated into customer specified designs, helping deliver more environmentally friendly solutions. EM1 identified alternate environmental benefits of new technologies, in the form of reducing noise pollution, that had previously limited their ability to use particular machinery overnight. While the newer machines were more expensive and in certain situations slower than older machines, being able to run by themselves, through the night, provided economic, environmental and social benefits, due to removing the need for a dedicated night shift. 
IJ2 identified an alternate motivator for more energy efficient machinery, in terms of not exceeding the capacity of the local electricity substation, which limited business growth and could incur charges in order to increase capacity. However, while the equipment was more energy efficient and the company was able to get interest free loans to facilitate investment, it was not possible to justify the cost of new machinery with energy and processing time savings alone. Finally, one of the more direct examples of PI contributing to environmental and economic benefits was provided by EM2 (similar examples were present in other cases). EM2 illustrated how they were able to make PI to better utilize raw material, helping reduce process waste through revising the manufacturing process. By converting more of the raw material into products, they were able to make more money, while at the same time reduce the amount of material that was discarded, so contributing environmental benefits.

Complementing the contracting of productive resources, service providers provided the firms indirect resources to increase the scope of activities that could be completed by the firm. By working with a design consultancy, IJ2 were able to contribute to the fundamental redesign of customer products, that was not possible with their existing knowledge, capabilities and credibility. When a design consultant identified problems with customer designs, customers were more willing to accept the need for changes, compared to a contracted manufacturer (IJ2). Additional forms of indirect supplier involvement where support service suppliers, who provided training in improvement techniques that were directed to both operational and improvement staff (IJ1, BC). Such training provided direction and structure for operational staff to make improvements to operational processes using particular methods, such as lean or developing procedures as part of an ISO 9001 quality management accreditation. Within each case, to realise benefits from such support, it was necessary for the training to be effectively integrated into production processes. IJ1 demonstrated that when involvement with support services involved customers, it might be necessary to communicate the results of improvement activities, which motivated the implementation of what was learnt in training. However, they also illustrated that without engagement of operational staff, changes in practice may be short lived and improvement results superficial.

While the involvement with external parties had potential to provide significant benefits for each firm, there was a key factors that affected whether firms were able to realise benefits from involvement with external parties. This was whether the introduction of new business and involvement with customers or suppliers provide opportunities to develop and make improvements to internal processes. If this factor was not satisfied, firms had greater difficulty in releasing benefits from involvement with customers and suppliers. Critically, it was not sufficient for firms to identify improvement opportunities to process or product designs to realise benefits. It was necessary for opportunities to be integrated into revenue generating processes in order for them to benefited process stakeholders. This was illustrated by training (IJ1) or 
involvement with technologies suppliers (SI), that took resources, but did not translate into reduced production costs, added customer value or securing new business (economic performance). While providing some social benefits in the form of personal development in SI and IJ1, without learning affecting operational processes and operators rejecting changes to practice, the overall benefits were marginal and temporary. Table 2 provides evidence of how PI within each of the case companies related to each of the identified stakeholders and benefits related to the Triple Bottom Line.

$* *$ insert Table 2 around here**

\section{Discussion}

The presented case evidence illustrates the critical role of stakeholders within PI activities in the context of SMEs. Findings suggest that defining PI too tightly, such as simply waste reduction, can result in limited benefits, lead to resistance of operational staff and management seeing limited value in PI. Rather than viewing the benefits that are realised from PI activities as shortterm cost savings, defining the benefits as being realised by all involved and affected, stakeholder theory provides a more holistic, longer-term view of PI. A stakeholder theory informed conceptualisation of PI provides a foundation and justification for engaging a range of stakeholders, even if PI tends to focus internally. Greater involvement of varied stakeholders provides more opportunities for improvements that have potential to provide longer-term benefits. Through greater involvement of varied stakeholders, greater awareness is built on the variety of benefits that can be realised from PI. By categorizing the varied PI benefits in terms of the TBL, there is an explicit link between stakeholder theory and TBL, so justifying why attention on PI is important for the organization and wider stakeholders. By defining salient stakeholders as a fundamental component of PI provides a view that is not only focused upon short-term reductions in cost, but the longer-term development of both internal and external relations that build firm competitiveness (Barnett 2007).

\section{**insert Figure 1 about here**}

Figure 1 illustrates how salient stakeholders may contribute to and benefit from PI. The findings presented in Table 2, focusing on the primary stakeholders is largely consistent with Freeman's (1984) managerial view, where stakeholders are those required to produce products (suppliers and employees) or buy the product (customers). This finding in itself is not new, being consistent with the work on quality management (Powell 1995, Kaynak 2003, Aquilani et al. 2017). However, the explicit stakeholder perspective focuses on defining not simply the need for involvement of stakeholders, but how that involvement relates explicitly to the nature of PI activities. The stakeholder perspective also begins to identify the direct and indirect benefits 
other parties are able to realise from engagement in PI, highlighting the need to formally include stakeholders when defining and engaging in PI.

The work introduces stakeholder theory to the exploration of operational PI. Instead of PI as a narrowly defined practice focused on improving consistency and reducing waste, more attention is given to the social activities that constitute PI. Through greater involvement of stakeholders, and defining benefits in terms of the TBL, there are more opportunities for SMEs to communicate internal developments with wider organisational stakeholders. Through demonstrating that a firm performs well not only in relation to cost, but also through benefiting staff, suppliers, and the environment (Donaldson and Preston 1995), firms are able to contribute to their and their customers' sustainability targets. Through understanding PI from a stakeholder perspective, there is potential to explore the implementation of a range of initiatives, including corporate social responsibility (Barnett 2007, Moratis 2017) to ensure outcomes provide the benefits required by the organization, as well as its salient stakeholders (Mitchell et al. 1997). Through acknowledging the role and opportunities to benefit varied stakeholders, this stakeholder perspective can facilitate the building of support for PI initiatives not only from within an organisation's management, but also operational staff, and the wider horizon of salient stakeholders.

\section{Conclusion}

The introduction of stakeholder theory and the TBL to PI makes a number of contributions to PI, stakeholder theory and the TBL. For PI, the perspective gives explicit attention to the contribution of a range of parties and the impact that can have on the outcomes of PI. Rather than viewing external parties as merely playing a role in early stages of PI, as presented in previous literature (Powell 1995, Kaynak 2003), a wider range of stakeholders can be identified and also categorized depending on the nature of their involvement. Such categorization can help to identify salient parties that are able to provide short and also longer term economic benefits. This is consistent with Matthews and Marzec's (2017) view of the need to match PI selection criteria to the requirements of a particular business that include the needs of varied stakeholders allowing the delivery of TBL benefits. Secondly, in combination with short and long-term benefits that can be realised by various stakeholders, stakeholder theory can also help broaden the scope of PI thinking. Rather than taking a management view (Freeman 1984), attention can be given to identifying parties that may be able to contribute in the future, such as suppliers and other salient stakeholders that may be able to contribute to winning new types of business. This provides both contributions to operations management theory, but also practical contributions to how SME management should define, select and practice PI, by taking account of a range of stakeholder needs.

In addition to these contributions made to operations management theory, the work is also able to 
contribute to stakeholder theory due to the insights from PI. Firstly, the research draws into question Barnett's (2007, p.800) view that "PI efforts merit categorization with other standard corporate investments in improving operational efficiency" rather than broader stakeholder concepts such as corporate social responsibility or TBL improvements. Rather than simply focusing on the direct benefits realised from PI, attention can focus instead on the indirect benefits realised by a variety of stakeholders. This applies particularly within the case of SMEs with their need to prioritise their operational staff. By viewing PI from a stakeholder perspective, efforts may not wholly be focused on waste, cost or cycle time reduction, instead giving emphasis to benefiting stakeholders that may indirectly improve a firm's economic performance, via social benefits. Norman and McDonald (2004) criticized the TBL for the social elements of performance being difficult to measure, however, prioritizing social well-being of operators can provide a firm with an important social license to operate. IJ2 provided an example of PI where the financial benefits were difficult to estimate, but considered the removal of a repetitive job from an operator was the right thing to do. Within such scenarios, exploring the benefits realised from PI in terms of the TBL provides a relevant framework for selecting and justifying PI activities, away from tightly defined financial benefits. Finally, PI provides an operational context that directly links stakeholder involvement with operational processes and TBL performance, so providing a rich context in which to explore stakeholder theory empirically to verify frameworks presented by Donaldson and Preston (1995), amongst others. The research also specifically addresses concerns of Despeisse et al. (2012), by providing mechanisms through which firms can link operational activities to the delivery of improvements across the TBL.

The conceptual model presented in Figure 1 begins to extend or indeed reframe established models of stakeholder theory (Freeman 1984). Rather than viewing the range of stakeholders as merely having a single, bidirectional relationship with the firm, there is attention on how individual stakeholders may relate to one another, consistent with a systems oriented view (Radnor et al. 2012). Consequently, rather than simply viewing the management of individual stakeholders as a focus of attention, management of a number of stakeholders simultaneously and the development of relationships between stakeholders is highlighted (Tate and Bals 2016). While strategic stakeholder management is more relevant to larger firms (Panwar et al. 2016), smaller firms may be able to build greater network power, that key stakeholders will, over time, depend upon. Such a view may aid further exploration and build understanding of how a variety of salient stakeholders contribute to improved, long-term, TBL performance, and which activities benefit most from involvement of particular stakeholders.

In conclusion, stakeholder theory provides an interesting perspective from which to view PI activities, broadening definitions, supporting long-term firm development and delivering improvements across the TBL. There are considerable opportunities for both theoretical and empirical investigations of the role of stakeholders in PI. The findings represent a first exploration into PI from a novel perspective. Further explorations could be more deliberate in 
identifying and discussing additional stakeholders to investigate their role in PI. One instance identified within the research was the impact of noise pollution on the local community, similar to examples provided by Freeman (1984). Future research could explore whether greater attention on stakeholder management, and the TBL, could provide additional benefits for the firm. Building on this paper, further research within larger firms would also help to develop theory on PI from a stakeholder theory perspective. Panwar et al. (2016) highlights the limitation of the current research due to SMEs being under less scrutiny from external stakeholders such as NGOs, which would be addressed by conducting research in larger firms. Notwithstanding this limitation, the current research on stakeholder impacts on the TBL in SMEs has been able to open the door on valuable new insights.

\section{References:}

Amundson, S.D. 1998. "Relationships between theory-driven empirical research in operations management and other disciplines." Journal of Operations Management 16 (4):341-359.

Anand, G., P.T. Ward, and M.V. Tatikonda. 2010. "Role of explicit and tacit knowledge in Six Sigma projects: An empirical examination of differential project success." Journal of Operations Management 28 (4):303-315.

Aquilani, Barbara, Cecilia Silvestri, Alessandro Ruggieri, and Corrado Gatti. 2017. "A systematic literature review on total quality management critical success factors and the identification of new avenues of research." The TQM Journal 29 (1):184213.

Barnett, Michael L. 2007. "Stakeholder influence capacity and the variability of financial returns to corporate social responsibility." Academy of Management Review 32 (3):794-816.

Benner, M.J., and F. M. Veloso. 2008. "ISO 9000 practices and financial performance: A technology coherence perspective." Journal of Operations Management 26 (5):611629.

Benner, Mary J., and Michael Tushman. 2002. "Process Management and Technological Innovation: A Longitudinal Study of the Photography and Paint Industries." Administrative Science Quarterly 47 (4):676-706.

Boer, H., M. Holweg, M. Kilduff, M. Pagell, R. Schmenner, and C. Voss. 2015. "Making a meaningful contribution to theory." International Journal of Operations \& Production Management 35 (9):1231-1252. doi: 10.1108/IJOPM-03-2015-0119.

Chakravorty, S.S. 2009. "Six Sigma failures: An escalation model." Operations Management Research 2 (1):44-55. doi: 10.1007/s12063-009-0020-8.

Childe, Stephen J. 2011. "Case studies in operations management." Production Planning \& Control 22 (2):pp.107.

De Mast, Jeroen, and Joran Lokkerbol. 2012. "An analysis of the Six Sigma DMAIC method from the perspective of problem solving." International Journal of Production Economics 139 (2):604-614. 
Despeisse, M., F. Mbaye, P. D. Ball, and A. Levers. 2012. "The emergence of sustainable manufacturing practices." Production Planning and Control 23 (5):354-376. doi: 10.1080/09537287.2011.555425.

Donaldson, Thomas, and Lee E Preston. 1995. "The stakeholder theory of the corporation: Concepts, evidence, and implications." Academy of management Review 20 (1):6591.

Dües, Christina Maria, Kim Hua Tan, and Ming Lim. 2013. "Green as the new Lean: how to use Lean practices as a catalyst to greening your supply chain." Journal of cleaner production 40:93-100.

Eisenhardt, K.M. 1989. "Building Theory from Case Study Research." Academy of Management Review 14 (4):532-550.

Elkington, J. 1999. Cannibals with Forks: The Triple Bottom Line of 21st Century Business. Oxford: Capstone.

Freeman, R Edward, Jeffrey S Harrison, Andrew C Wicks, Bidhan L Parmar, and Simone De Colle. 2010. Stakeholder theory: The state of the art: Cambridge University Press.

Freeman, RE. 1984. Strategic management: A stakeholder approach. Marshfield: Mass.:Pitman.

Handfield, R.B., and S.A. Melnyk. 1998. "The scientific theory-building process: a primer using the case of TQM." Journal of Operations Management 16 (4):321-339. doi: Doi: 10.1016/s0272-6963(98)00017-5.

Hasnas, John. 2013. "Whither stakeholder theory? A guide for the perplexed revisited." Journal of Business Ethics 112 (1):47-57.

Hollos, Daniel, Constantin Blome, and Kai Foerstl. 2012. "Does sustainable supplier cooperation affect performance? Examining implications for the triple bottom line." International Journal of Production Research 50 (11):2968-2986.

Hudson, M., J. Lean, and P. A. Smart. 2001. "Improving control through effective performance measurement in SMEs." Production Planning \& Control: The Management of Operations 12 (8):804 - 813.

Kannan, Devika. 2017. "Role of multiple stakeholders and the critical success factor theory for the sustainable supplier selection process." International Journal of Production Economics. doi: http://dx.doi.org/10.1016/j.ijpe.2017.02.020.

Kaynak, H. 2003. "The relationship between total quality management practices and their effects on firm performance." Journal of Operations Management 21 (4):405-435. doi: Doi: 10.1016/s0272-6963(03)00004-4.

Kumar, M., J. Antony, R.K. Singh, M.K. Tiwari, and D. Perry. 2006. "Implementing the Lean Sigma framework in an Indian SME: a case study." Production Planning \& Control 17 (4):407-423.

Matthews, R.L., B.L. MacCarthy, and C. Braziotis. 2017. "Organisational learning in SMEs: a process improvement perspective." International Journal of Operations and Production Management 37 (7). doi: http://dx.doi.org/10.1108/IJOPM-09-2015-0580.

Matthews, R.L., and P.E. Marzec. 2017. "Continuous, Quality and Process Improvement: Disintegrating and Reintegrating Operational Improvement?" Total Quality Management \& Business Excellence 28 (3-4):296-317. doi: 10.1080/14783363.2015.1081812. 
McAdam, Rodney, and Brendan Lafferty. 2004. "A multilevel case study critique of six sigma: statistical control or strategic change?" International Journal of Operations \& Production Management 24 (5):530-549.

Mitchell, Ronald K, Bradley R Agle, and Donna J Wood. 1997. "Toward a theory of stakeholder identification and salience: Defining the principle of who and what really counts." Academy of management review 22 (4):853-886.

Moratis, Lars. 2017. "The credibility of corporate CSR claims: a taxonomy based on ISO 26000 and a research agenda." Total Quality Management \& Business Excellence 28 (1-2):147-158.

Noke, H., and M. Hughes. 2010. "Climbing the value chain: Strategies to create a new product development capability in mature SMEs." International Journal of Operations \& Production Management 30 (2):132-154.

Norman, W., and C. MacDonald. 2004. "Getting to the bottom of "Triple Bottom Line"." Business Ethics Quarterly 14 (2):243-262+345-346.

Osborne, Stephen P, Zoe Radnor, Tony Kinder, and Isabel Vidal. 2015. "The SERVICE Framework: A Public service dominant Approach to Sustainable Public Services." British Journal of Management 26 (3):424-438.

Panwar, Rajat, Erlend Nybakk, Eric Hansen, and Jonatan Pinkse. 2016. "The effect of small firms' competitive strategies on their community and environmental engagement." Journal of Cleaner Production 129:578-585.

Powell, T.C. 1995. "Total quality management as competitive advantage: A review and empirical study." Strategic Management Journal 16 (1):15-37. doi: 10.1002/smj.4250160105.

Radnor, H.A. 2001. Researching your professional practice: doing interpretive research, Doing qualitative research in educational settings. Buckingham: Open University Press.

Radnor, Z.J., M. Holweg, and J. Waring. 2012. "Lean in healthcare: the unfilled promise?" Social Science \& Medicine 74 (3):364-371.

Samson, D., and M. Terziovski. 1999. "The relationship between total quality management practices and operational performance." Journal of Operations Management 17 (4):393-409. doi: Doi: 10.1016/s0272-6963(98)00046-1.

Schroeder, R.G., K. Linderman, C. Liedtke, and A.S. Choo. 2008. "Six Sigma: Definition and underlying theory." Journal of Operations Management 26 (4):536-554.

Shamsuzzoha, A, C Toscano, LM Carneiro, Vikas Kumar, and Petri Helo. 2016. "ICT-based solution approach for collaborative delivery of customised products." Production Planning \& Control 27 (4):280-298.

Stuart, I., D. McCutcheon, R. Handfield, R. McLachlin, and D. Samson. 2002. "Effective case research in operations management: a process perspective." Journal of Operations Management 20 (5):419-433. doi: Doi: 10.1016/s0272-6963(02)00022-0.

Tate, Wendy L, and Lydia Bals. 2016. "Achieving Shared Triple Bottom Line (TBL) Value Creation: Toward a Social Resource-Based View (SRBV) of the Firm." Journal of Business Ethics:1-24.

Ten Bos, R, and D Bevan. 2011. "Sustainability." Painter-Morland, M.; Bos, R. ten (ed.), Business Ethics and Continental Philosophy:285-305. 
Tyler, Melissa, and Adrian Wilkinson. 2007. "THE TYRANNY OF CORPORATE SLENDERNESS:CORPORATE ANOREXIA" AS A METAPHOR FOR OUR AGE." Work, Employment and Society 21 (3):537-549.

Voss, C., N. Tsikriktsis, and M. Frohlich. 2002. "Case research in operations management." International Journal of Operations \& Production Management 22 (2):195-219.

Walker, H., D. Chicksand, Z. Radnor, and G. Watson. 2015. "Theoretical perspectives in operations management: an analysis of the literature." International Journal of Operations \& Production Management 35 (8):1182-1206.

Yin, R.K. 2009. Case Study Research: Design and Methodology (Applied Social Research Methods). 4th ed. Thousand Oaks, CA: Sage Publications Inc. 